\title{
ANALISIS KEPUASAN KONSUMEN DAN STRATEGI PENGEMBANGAN AGROWISATA KEBUN BUAH CEPOKO DI KECAMATAN GUNUNG PATI KOTA SEMARANG
}

\author{
Yanti Yosepha Rufina Br Sembiring ${ }^{1}$, Sunarso Sunarso ${ }^{2}$ dan Wiludjeng Roessali ${ }^{2}$ \\ ${ }^{1}$ Dinas Pertanian Kota Semarang \\ ${ }^{2}$ Fakultas Peternakan dan Pertanian, Universitas Diponegoro \\ Email: yanti.yosepha@gmail.com
}

Diterima 9 Juli 2019, disetujui 16 Desember 2019

\begin{abstract}
ABSTRAK
Agrowisata memiliki tujuan yaitu untuk memberikan ilmu pengetahuan, edukasi, pengalaman rekreasi dan mengenal hubungan usaha dibidang pertanian. Kebun Buah Cepoko merupakan salah satu Kebun Satuan Kerja milik UPTD. Kebun Dinas Pertanian yang sangat potensial untuk dijadikan Agrowisata. Penelitian ini bertujuan untuk menganalisis kepuasan pengunjung terhadap perkembangan Agrowisata Kebun Buah Cepoko, menganalisis Faktor Internal dan Eksternal yang mempengaruhi pengembangan Agrowisata Kebun Buah Cepoko dan menetapkan strategi dalam pengembangan Agrowisata Kebun Buah Cepoko. Penelitian ini dilaksanakan di Unit Pelaksana Teknis Dinas (UPTD) Kebun Dinas, Kebun Buah Cepoko, Kecamatan Gunung Pati. Analisis data yang digunakan untuk menjawab tujuan yaitu Analisis CSI, Analisis Matriks Evaluasi Faktor Internal dan Eksternal dan Analisis SWOT. Hasil penelitian menunjukkan indeks kepuasan pengunjung Agrowisata Kebun Buah Cepoko, diketahui nilai CSI adalah 77,81 persen sehingga dapat dikatakan bahwa secara keseluruhan pengunjung Agrowisata Kebun Buah Cepoko puas terhadap atribut Kebun Buah Cepoko. Posisi Agrowisata Kebun Buah Cepoko berdasarkan kondisi internal dan eksternal berada pada kuadran I yang menunjukkan bahwa Agrowisata Kebun Buah Cepoko berada pada situasi yang sangat menguntungkan karena memiliki kekuatan dan peluang yang dapat dimanfaatkan sebaik-baiknya dengan cara menerapkan strategi pertumbuhan agresif.
\end{abstract}

Kata Kunci: Agrowisata, Kebun Buah, Cepoko, CSI, SWOT

\begin{abstract}
Agrotourism has its main purpose to provide knowledge, education, recreational experience, and introduce business relation in agriculture sector. Cepoko Fruit Garden is one of UPTD's work unit garden which is highly potential to be developed as agrotourism. This research aims to analyze visitor's satisfaction of Cepoko Fruit Garden Agrotourism development, analyze the internal and external factors that affect its development, and establish the strategy to develop Cepoko Fruit Garden Agrotourism. This research was conducted in work unit garden of UPTD (Unit Pelaksana Teknis Dinas/Office Technical Implementation Unit), Cepoko Fruit Garden, Gunung Pati District. Data analysis method that is used in this research is CSI Analysis, Internal and External Evaluation Matrix Analysis, and SWOT Analysis. According to CSI Analysis, the research result shows that the visitor satisfaction index of Kebun Buah Cepoko Agrotourism is 77,81 percent. It can be concluded that overall visitors of Cepoko Fruit Garden Agrotourism are satisfied with its attributes. According to the internal and external condition assessment, Cepoko Fruit Garden Agrotourism marked its position at the first quadrant. This shows that Cepoko Fruit Garden Agrotourism is in a very favorable situation because it has the strength and opportunity that can be utilized as well as possible by implementing aggressive growth strategies.
\end{abstract}

Keywords: Agrotourism, Fruit Garden, Cepoko, CSI, SWOT 


\section{PENDAHULUAN}

Agrowisata merupakan sektor yang penting dalam perekonomian Indonesia, karena agrowisata atau wisata pertanian merupakan cara alternatif untuk meningkatkan pendapatan dan menggali potensi ekonomi petani kecil dan masyarakat pedesaan (Puspitasari, 2018). Wisata Agro atau Agrowisata merupakan salah satu jenis pariwisata yang potensial dikembangkan di Indonesia. Sebagai negara agraris, Indonesia memiliki kekayaan alam dan hayati yang sangat beragram. Kekayaan tersebut apabila dikelola dengan tepat dapat dijadikan andalan perekonomian nasional. Komoditas pertanian (mencakup tanaman pangan, hortikultura, perkebunan, kehutanan, peternakan dan perikanan) dengan keragaman dan keunikannya yang bernilai tinggi serta diperkuat oleh kekayaan kultural yang sangat beragam mempunyai daya tarik kuat sebagai wisata agro (Departemen Pertanian, 2004). Semua aspek tersebut memiliki peluang besar untuk menjadi andalan dalam perekonomian Indonesia.

Kebun Buah Cepoko merupakan salah satu kebun satuan kerja milik Unit Pelaksana Teknis Dinas (UPTD) Kebun Dinas Pertanian Kota Semarang yang terletak di Kelurahan Cepoko, Kecamatan Gunung Pati, Kota Semarang, yang semula merupakan kebun tanaman kelapa yang sudah tidak produktif, kemudian pada tahun 2011 dirubah menjadi kebun buah dengan tanaman pokok Lengkeng dan Jambu Kristal. Kebun Buah Cepoko mempunyai luas 3,5 ha yang ditanami tanaman Lengkeng, Jambu Kristal, Durian dan Sirsat Madu. Kebun Buah Cepoko juga berfungsi sebagai tempat produksi bibit tanaman, sebagai tempat edukasi (pembelajaran) serta sumber informasi untuk dunia pendidikan khususnya dibidang pertanian mulai dari taman kanak-kanak sampai tingkat perguruan tinggi. Selain itu Kebun Buah Cepoko juga sebagai Agrowisata yang sangat potensi untuk dikembangkan karena gaya hidup masyarakat yang ingin kembali ke alam (back to nature) dan lokasi Kebun Buah
Cepoko sangat strategis. Kebun Buah Cepoko mempunyai hamparan kebun/lahan pertanian yang memiliki keindahan alam dan keindahan taman serta menawarkan wisata petik buah sendiri langsung di pohon.

Kebun Buah Cepoko dikelola oleh Kelompok Tani Gunung Subur yang terdiri dari 17 Petani dengan sistem bagi hasil dengan Dinas Pertanian Kota Semarang. Tujuan utama petani mengelola lahan pertanian adalah untuk memenuhi kebutuhan dan untuk meningkatkan tarap hidup keluarganya. Petani Kebun Cepoko mempunyai peran mengatur dan memelihara pertumbuhan tanaman. Pemeliharaan tanaman merupakan salah satu unsur dalam budidaya untuk meningkatkan kuantitas dan kualitas produksi (Sunanto, 2011). Pengaturan pertumbuhan tanaman yang dilakukan Petani Kebun Cepoko meliputi penyiangan, pembersihan gulma, pemupukan, penyiraman, pemberantasan hama penyakit tanaman, dan pemungutan hasil panen. Budiarti (2013) meneliti tentang Pengembangan Agrowisata berbasis masyarakat pada usahatani terpadu guna meningkatkan kesejahteraan petani dan keberlanjutan sistem pertanian, hasil penelitian menunjukkan bahwa masyarakat Cikahuripan membudidayakan budaya pertanian yang khas dan peningkatan kerja sama dengan pihak terkait untuk pengembangan agrowisata berbasis masyarakat.

Faktor-faktor yang diperkirakan berpengaruh terhadap Pengembangan Agrowisata di Kebun Buah Cepoko dipilah ke dalam dua kelompok besar yaitu kelompok faktor Internal dan Eksternal. Kelompok faktor Internal terbagi ke dalam dua kategori yaitu faktor kekuatan dan kelemahan, sedangkan kelompok faktor Eksternal terbagi ke dalam kategori faktor peluang dan tantangan (David, 2002).

Setiap manusia dalam kehidupan seharihari tidak terlepas dari kegiatan rutin ditempat kerja, di rumah, maupun di tempat lain. Aktivitas rutin tersebut dapat menimbulkan suatu kejenuhan pada diri manusia. Untuk mengatasi rasa jenuh tersebut, manusia berusaha melakukan kegiatan untuk 
menghibur diri dan melupakan sejenak kegiatan rutinnya. Salah satu kegiatan yang dilakukan sebagian orang untuk menghilangkan kejenuhan itu adalah rekreasi ataupun berwisata.

Agrowisata merupakan salah satu bentuk dari rural tourism yang menawarkan kegiatan pertanian sebagai daya tarik wisata serta melibatkan penduduk lokal dalam perencanaan hingga pengelolaan kawasan agrowisata. Menurut Jolly dan Reynolds (2005). Agrowisata adalah suatu bisnis yang dilakukan oleh para petani yang bekerja disektor pertanian bagi kesenangan dan edukasi para pengunjung (Putra et al., 2015). Agrowisata menghadirkan potensi sumber pendapatan dan meningkatkan keuntungan masyarakat. Pengunjung kawasan Agrowisata dapat berhubungan langsung dengan para petani dan mendukung peningkatan produk-produk pertanian secara tidak langsung.

Upaya pengembangan agrowisata pedesaan yang memanfaatkan potensi pertanian, dan melibatkan masyarakat pedesaan, dapat berfungsi sebagai pemberdayaan masyarakat selaras dengan pemberdayaan masyarakat berbasis pariwisata. Pemberdayaan masyarakat dimaksud adalah agrowisata yang dapat mengikutsertakan peran dan aspirasi masyarakat pedesaan selaras dengan pendayagunaan potensi sumber daya alam dan sumber daya manusia yang dimilikinya.

Eksistensi Agrowisata Kebun Buah Cepoko tidak lepas dari peran pengunjung Agrowisata tersebut. Faktor utama penentu kepuasan pengunjung adalah persepsi pengunjung terhadap kualitas jasa. Dalam jangka panjang memungkinkan Agrowisata untuk memahami dengan seksama harapan pengunjung serta kebutuhan mereka. Dengan demikian Agrowisata dapat meningkatkan kepuasan pengunjung dimana Agrowisata memaksimumkan pengalaman pengunjung yang menyenangkan. Pada gilirannya kepuasan dapat menciptakan kesetiaan atau loyalitas pengunjung kepada Agrowisata yang memberikan kualitas memuaskan.

Potensi Wisata Agro yang sangat tinggi di Kebun Buah Cepoko belum sepenuhnya dikembangkan dan dimanfaatkan secara optimal. Objek dan daya tarik wisata belum digali secara baik, upaya pengelolaan objek wisata yang dilaksanakan dalam rangka pengembangan pariwisata masih terbatas. Oleh karena itu, pengembangan potensi wisata di kawasan Agrowisata Kebun Buah Cepoko perlu dilakukan. Memperhatikan kondisi yang ada tujuan penelitian ini adalah menganalisis kepuasan pengunjung terhadap perkembangan agrowisata kebun buah cepoko dan menganalisis Faktor Internal dan Eksternal yang mempengaruhi pengembangan Agrowisata di Kebun Buah Cepoko Kecamatan Gunung Pati serta menetapkan strategi dalam pengembangan agrowisata di Kebun Buah Cepoko Kecamatan Gunung Pati.

\section{METODE PENELITIAN}

\section{Metode Penelitian dan Pengambilan Sampel}

Penelitian ini dilaksanakan pada Bulan April-Mei 2018 berlokasi di Agrowisata Kebun Buah Cepoko Kecamatan Gunung Pati. Pemilihan lokasi dilakukan dengan sengaja (purposive) dengan pertimbangan bahwa Kebun Buah Cepoko telah mengembangkan konsep Agrowisata. Populasi dalam penelitian ini adalah wisatawan domestik yang mengunjungi kawasan Agrowisata Kebun Buah Cepoko. Pengambilan sampel (responden) dilakukan dengan pengambilan secara non-acak (non- probability sampling) dengan metode pengambilan sampel menggunakan Accidental sampling. Pengambilan secara non-acak (non-probaility sampling) yaitu semua objek penelitian tidak memiliki peluang yang sama untuk dipilih sebagai sampel, karena dalam pelaksanaannya digunakan pertimbangan hal-hal tertentu yang dikenakan kepada sub kelompok.

Responden yang diperlukan dalam penelitian ini adalah pengunjung yang telah melakukan aktivitas wisata dan akan meninggalkan tempat wisata, sehingga dapat diketahui pengalaman setelah berwisata. Adapun kriteria responden pada tahap ini 
adalah pengunjung Agrowisata Kebun Buah Cepoko yang berusia 20 tahun ke atas, dengan pertimbangan responden dapat mengerti pertanyaan-pertanyaan yang ada dalam kuesioner. Pada penelitian Agrowisata, jumlah populasi tidak diketahui sehingga tidak memiliki sampling frame. Dengan demikian, penentuan jumlah sampel mengacu pada rumus Durbarry (2016):

$$
\begin{aligned}
& n=\frac{Z^{2} \times \sigma \times(1-\sigma)}{E^{2}} \\
& n=\frac{1,96^{2} \times 0,5 \times(1-0,5)}{10 \%^{2}} \\
& n=96,4
\end{aligned}
$$

Keterangan

$\mathrm{Z}=$ nilai $\mathrm{Z}$ pada tabel $\alpha / 2$, pada penelitian ini tingkat kepercayaan $(\alpha)$ yang digunakan adalah $95 \%$

$\mathrm{n}=$ jumlah sampel minimal yang dibutuhkan

$\sigma=$ standar deviasi populasi, angka 0,5 digunakan sebagai ketetapan pada populasi yang tidak diketahui jumlahnya, yang telah diterapkan pada penelitian ilmu sosial

$\mathrm{E}=$ batas besar kesalahan maksimal dalam penelitian. Nilai E yang digunakan dalam penelitian ini adalah $10 \%$

Berdasarkan perhitungan tersebut, jumlah minimal sampel yang dibutuhkan adalah 96 pengunjung. Namun, keabsahan hasil uji statistik dapat ditingkatkan dengan menambahkan jumlah sampel yang diambil (Habiby, 2017). Oleh karena itu, pada penelitian ini mempergunakan 100 sampel yang terdiri dari Karyawan UPTD. Kebun Dinas Pertanian, Petani Penggarap Kebun Buah Cepoko, Pegawai Dinas Pertanian, Tokoh Masyarakat dan Pengunjung Kebun Buah Cepoko.

\section{Karakteristik Wisatawan}

Melakukan analisis deskriftif karakteristik wisatawan Agrowisata Kebun Buah Cepoko. Wisatawan dikelompokkan berdasarkan usia, jenis kelamin, status perkawinan, tingkat pendidikan dan pekerjaan.

\section{Analisis Kepuasan Pengunjung}

Customer Satisfication Index dalam Bahasa Indonesia disebut Indeks Kepuasan Konsumen atau sering disebut CSI merupakan metode yang digunakan untuk mengetahui tingkat kepuasan konsumen. Metode ini memiliki kelebihan antara lain efisiensi (tidak hanya tingkat kepuasan tetapi juga informasi tentang atribut yang perlu diperbaiki), mudah digunakan dan sederhana karena menggunakan skala yang memiliki sensitivitas dan reliabilitas yang cukup tinggi (Anggraini et al., 2015). Metode CSI juga berguna untuk internal perusahaan. Melalui metode CSI, perusahaan dapat memantau perbaikan layanan dan motivasi karyawan untuk memberikan kepuasan bagi konsumen (Syukri, 2014).

Kepuasan pengunjung dianalisis dengan menggunakan Customer Satisfication Index (CSI). Customer Satisfication Index (CSI) bertujuan untuk mengetahui tingkat kepuasan pengunjung secara menyeluruh dengan melihat tingkat kepentingan dari atributatribut produk atau jasa. Mengetahui besarnya CSI, maka dapat dilakukan langkah-langkah sebagai berikut (Aritonang, 2005). Ada empat langkah dalam perhitungan Customer Satisfication Index, yaitu:

Langkah pertama menentukan Mean Imprtance Score (MIS) dan Mean Satisfication Score (MSS). Nilai ini didapat dari nilai rata-rata tingkat kepentingan dan nilai rata-rata kinerja tiap responden.

$$
M I S=\frac{\sum_{i=1}^{n} Y i}{n} \text { dan } M S S=\frac{\sum_{i=1}^{n} X i}{n}
$$

Keterangan:

$\mathrm{n}=$ Jumlah responden

$\mathrm{Yi}=$ Nilai kepentingan atribut ke $\mathrm{i}$

$\mathrm{Xi}=$ Nilai kinerja atribut ke $\mathrm{i}$

Langkah kedua membuat Weight Factors (WF). Bobot ini merupakan persentase nilai MIS per atribut terhadap total MIS seluruh atribut. Dimana $p=$ atribut kepentingan ke- $p$ dan $\mathrm{i}=$ atribut ke- $\mathrm{i}$ 


$$
W F i=\frac{M I S i}{\sum_{i=1}^{p} M I S i} \times 100 \%
$$

Langkah ketiga membuat Weight Score (WS) bobot ini merupakan perkalian antara WF dengan rata-rata Mean Satisfication Score (MSS).

$\mathrm{WSi}=\mathrm{WFi}$ x MSSi

Langkah keempat menentukan Customer Satisfication Index (CSI)

$$
C S I=\frac{\sum_{i=1}^{p} W S i}{H S} \times 100 \%
$$

Dimana:

$\mathrm{p} \quad$ : atribut kepentingan ke-p

HS : Skala maksimum yang digunakan

Perhitungan CSI dilakukan dengan membagi total nilai Weight Score (WS) dengan skala maksimum yang digunakan dalam penelitian yang umumnya skala maksimum yang digunakan yaitu 5 (Anggraini et al., 2015). Kriteria CSI disajikan pada Tabel 1.

Tabel 1. Kriteria CSI

\begin{tabular}{cc}
\hline Nilai CSI $(\%)$ & Kriteria CSI \\
\hline $0<\mathrm{CSI} \leq 34$ & Tidak Puas \\
$35<\mathrm{CSI} \leq 50$ & Kurang Puas \\
$51<\mathrm{CSI} \leq 65$ & Cukup Puas \\
$66<\mathrm{CSI} \leq 80$ & Puas \\
$81<\mathrm{CSI} \leq 100$ & Sangat Puas \\
\hline
\end{tabular}

(Wicaksana et al., 2013).

Analisis Strategi Pengembangan

Metode analisis yang digunakan dalam mengidentifikasi Strategi Pengembangan Agrowisata Kebun Buah Cepoko adalah dengan menggunakan analisis SWOT. Analisis SWOT adalah metode yang umum dan mudah digunakan untuk mengetahui faktor kelebihan sebagai pendukung dan kekurangan sebagai pembatas dari suatu objek wisata. Analisis SWOT diperlukan agar dapat mengetahui arahan strategi yang tepat dalam menjaga eksistensi Agrowisata Kebun Buah Cepoko.

\section{HASIL DAN PEMBAHASAN}

Karakteristik Wisatawan Agrowisata Kebun Buah Cepoko

Karakteristik konsumen dapat mempengaruhi perilaku dalam proses keputusan pembelian. Karakteristik pengunjung merupakan hal yang melekat pada diri pengunjung. Karakteristik pengunjung dalam penelitian ini terbagi menjadi jenis kelamin, usia, pekerjaan, tingkat pendidikan, daerah asal, dan status perkawinan. Karakteristik pengunjung Agrowisata Kebun Buah Cepoko dapat dilihat pada Tabel 2.

Tabel 2. Karakteristik Wisatawan Agrowisata

\begin{tabular}{|c|c|c|}
\hline Keterangan & Jumlah & $(\%)$ \\
\hline \multicolumn{3}{|l|}{ Jenis Kelamin } \\
\hline Laki-Laki & 40 & 40 \\
\hline Perempuan & 60 & 60 \\
\hline \multicolumn{3}{|l|}{ Usia } \\
\hline 15-24 tahun & 12 & 12 \\
\hline 25-34 tahun & 19 & 19 \\
\hline$>35$ tahun & 69 & 69 \\
\hline \multicolumn{3}{|l|}{ Status Perkawinan } \\
\hline Belum Kawin & 17 & 17 \\
\hline Kawin & 83 & 83 \\
\hline \multicolumn{3}{|l|}{ Tingkat Pendidikan } \\
\hline SD & 8 & 8 \\
\hline SMP & 9 & 9 \\
\hline SMA/SMK & 39 & 39 \\
\hline D3 & 9 & 9 \\
\hline S1 & 31 & 31 \\
\hline S2 & 3 & 3 \\
\hline S3 & 1 & 1 \\
\hline \multicolumn{3}{|l|}{ Pekerjaan } \\
\hline Wiraswasta/Pengusaha & 19 & 19 \\
\hline Pegawai Swasta & 29 & 29 \\
\hline PNS/BUMN & 18 & 18 \\
\hline Ibu Rumah Tangga & 19 & 19 \\
\hline Mahasiswa & 9 & 9 \\
\hline Petani & 6 & 6 \\
\hline \multicolumn{3}{|l|}{ Domisili } \\
\hline Semarang & 92 & 92 \\
\hline Luar Semarang & 8 & 8 \\
\hline
\end{tabular}
Kebun Buah Cepoko

Sumber: Data Primer diolah 
Berdasarkan karakteristik usia responden yang melakukan kunjungan ke Agrowisata Kebun Buah Cepoko yaitu sebesar 69\% berusia $>35,19 \%$ usia $25-34$ dan $12 \%$ usia 15-24 tahun. Berdasarkan jenis kelamin yang paling banyak adalah responden perempuan sebesar $60 \%$. Tingkat pendidikan responden wisatawan Agrowisata Kebun Buah Cepoko didominasi oleh wisatawan dengan tingkat pendidikan terakhirnya SMA/SMK yaitu sebesar 39\% dan Profesi terbesar adalah sebagai pegawai swasta dan wiraswasta.

\section{Perhitungan Customer Satisfaction Index (CSI)}

Berdasarkan hasil perhitungan indeks kepuasan pengunjung Agrowisata Kebun Buah Cepoko, diketahui nilai CSI adalah 77,81\%. Hasil perhitungan CSI dapat dilihat pada Tabel 3.

Tabel 3. Perhitungan Customer Satisfaction Index (CSI)

\begin{tabular}{|c|c|c|c|c|c|}
\hline No & Atribut & MSI & WF & MSP & TWS \\
\hline 1 & $\begin{array}{l}\text { Sumberdaya alam atau daya dukung alam merupakan aspek } \\
\text { utama dalam pengembangan agrowisata kebun buah cepoko }\end{array}$ & 4,27 & 0,05 & 4,34 & 0,20 \\
\hline 2 & $\begin{array}{l}\text { Fasilitas/sarana dan prasarana dalam pengembangan agrowisata } \\
\text { kebun buah cepoko }\end{array}$ & 4,28 & 0,05 & 4,34 & 0,20 \\
\hline & Wisata yang berbasis konservasi lingkungan hidup dan pendidi- & & & & \\
\hline 3 & $\begin{array}{l}\text { kan dapat mendorong pengembangan agrowisata kebun buah } \\
\text { cepoko }\end{array}$ & 4,30 & 0,05 & 4,31 & 0,20 \\
\hline 4 & Parkir luas & 4,54 & 0,05 & 1,81 & 0,09 \\
\hline 5 & Tempat sampah yang banyak & 4,14 & 0,04 & 2,44 & 0,11 \\
\hline 6 & Pondok/Gazebo & 4,16 & 0,04 & 4,05 & 0,18 \\
\hline 7 & Toilet & 4,14 & 0,04 & 3,90 & 0,17 \\
\hline 8 & Musholla & 4,17 & 0,04 & 4,02 & 0,18 \\
\hline 9 & Lokasi Agrowisata yang strategis & 4,51 & 0,05 & 4,73 & 0,23 \\
\hline 10 & Pemandu Wisata & 4,18 & 0,05 & 4,04 & 0,18 \\
\hline 11 & Tiket masuk murah & 4,35 & 0,05 & 4,57 & 0,21 \\
\hline 12 & Kafe/tempat makan dalam kebun buah & 4,05 & 0,04 & 2,38 & 0,10 \\
\hline 13 & Iklan/Promosi & 4,10 & 0,04 & 3,93 & 0,17 \\
\hline 14 & Leaflet/brosur & 4,10 & 0,04 & 3,90 & 0,17 \\
\hline 15 & Photo booth & 4,06 & 0,04 & 3,77 & 0,16 \\
\hline 16 & Papan pengumuman & 4,10 & 0,04 & 3,68 & 0,16 \\
\hline 17 & $\begin{array}{l}\text { Variasi/ragram produk yang dapat diperoleh di agrowisata kebun } \\
\text { buah cepoko }\end{array}$ & 4,13 & 0,04 & 4,06 & 0,18 \\
\hline 18 & Kontinuitas ketersediaan produk hasil kebun buah & 4,11 & 0,04 & 4,03 & 0,18 \\
\hline 19 & Akses transfortasi yang lancar ke agrowisata kebun buah cepoko & 4,49 & 0,05 & 4,66 & 0,23 \\
\hline 20 & Wahana rekreasi dalam agrowisata kebun buah cepoko & 4,13 & 0,04 & 4,00 & 0,18 \\
\hline 21 & $\begin{array}{l}\text { Dukungan masyarakat sekitar dalam pengembangan agrowisata } \\
\text { kebun buah cepoko }\end{array}$ & 4,43 & 0,05 & 4,50 & 0,21 \\
\hline 22 & Agrowisata sejenis di gunungpati & 4,09 & 0,04 & 4,03 & 0,18 \\
\hline & TOTAL & 92,90 & 1,00 & 85,50 & 3,89 \\
\hline & RATA-RATA & 4,22 & & 3,89 & \\
\hline & $\mathrm{CSI}=(3,89 / 5) \times 100 \%=77,81 \%$ & & & & \\
\hline
\end{tabular}

Sumber: Data Primer diolah

Keterangan:

MSI : Mean Score of Importance

WF : Weighted Factor

MSP : Mean Score of Performance

WS : Weight Score 
Berdasarkan Tabel 3 diketahui bahwa nilai CSI sebesar 77,81\% menunjukkan berada pada rentang skala $60 \%<\mathrm{CSI}<80 \%$, sehingga dapat dikatakan bahwa secara umum indeks kepuasan pengunjung untuk atribut yang diuji berada pada kriteria puas, oleh karena itu Agrowisata Kebun Buah Cepoko harus terus meningkatkan kinerja agar kepuasan pengunjung terhadap Agrowisata Kebun Buah Cepoko dapat meningkat lagi. Hal ini sesuai dengan penelitian Wicaksana et al. (2013) tentang Analisis Sikap dan Kepuasan Petani dalam menggunakan benih kentang bersertifikat dimana nilainya berada pada skala $60 \%<\mathrm{CSI}<80 \%$ dan penelitian (Tangkere, 2017) tentang kepuasan pengunjung terhadap kualitas pelayanan daerah wisata Puncak Temboan Tomohon.

Nilai rata-rata kinerja tertinggi adalah lokasi agrowisata yang strategis yaitu sebesar
4,73. Hal ini disebabkan karena Agrowisata Kebun Buah Cepoko lokasinya berada di depan jalan raya, akses ke lokasi mudah dijangkau karena dekat dengan kota dan akses transfortasi yang lancar ke Agrowisata Kebun Buah Cepoko. Sedangkan nilai rata-rata kinerja yang terendah adalah tempat parkir yaitu sebesar 1,81. Hal ini disebabkan karena Agrowisata Kebun Buah Cepoko mempunyai tempat parkir yang sempit sehingga tidak dapat menampung kendaraan dalam jumlah banyak.

\section{Analisis Strategi Pengembangan Agro- wisata Kebun Buah Cepoko}

Dalam menganalisis strategi pengembangan Agrowisata Kebun Buah Cepoko dapat menggunakan analisis SWOT. Maka dari itu menggunakan Faktor Internal dan Faktor Eksternal. Analisis Faktor Internal

Tabel 4. Matriks IFAS

\begin{tabular}{rlrrr}
\hline No & \multicolumn{1}{c}{ Faktor-Faktor Strategi Internal } & $\begin{array}{c}\text { Bobot } \\
(\mathbf{B})\end{array}$ & $\begin{array}{c}\text { Rating } \\
(\mathbf{R})\end{array}$ & B x R \\
\hline A & Kekuatan (Strength) & & & \\
1 & Tersedianya Sumber Daya Alam / daya dukung alam & 0,07 & 3,06 & 0,23 \\
& Konsep agrowisata yang berbasis konservasi, lingkungan & 0,07 & 3,00 & 0,21 \\
& hidup dan pendidikan & 0,07 & 3,00 & 0,22 \\
3 & Fasilitas Agrowisata Kebun Buah Cepoko & 0,07 & 3,30 & 0,24 \\
4 & Lokasi yang strategis & 0,07 & 2,92 & 0,19 \\
5 & Moral dan Motivasi karyawan & 0,06 & 2,96 & 0,19 \\
6 & Kesesuaian tenaga pemasaran dengan kebutuhan & 0,07 & 2,90 & 0,19 \\
7 & Pendidikan dan pengembangan bagi karyawan & 0,07 & 3,94 & 0,29 \\
\hline 8 & Ketersediaan modal untuk pengembangan usaha & & & $\mathbf{1 , 7 7}$ \\
\hline & Total & & & \\
\hline B & Kelemahan (Weakness) & 0,06 & 2,78 & 0,17 \\
1 & Promosi yang belum intensif dan gencar/ tingkat promosi & 0,06 & 3,02 & 0,18 \\
& masih kurang & 0,07 & 2,70 & 0,18 \\
2 & Variasi/ragam produk yang ditawarkan masih terbatas & 0,07 & 2,82 & 0,21 \\
3 & Kontinuitas ketersediaan produk hasil kebun buah & 0,06 & 2,76 & 0,16 \\
4 & Keterbatasan anggaran dalam pengembangan Agrowisata & 0,06 & 2,74 & 0,16 \\
& Kurangnya tenaga profesional dalam pengembangan & 0,06 & 2,90 & 0,18 \\
\hline & agrowisata & & & $\mathbf{1 , 2 3}$ \\
\hline 6 & Kuantitas tenaga kerja masih kurang & $\mathbf{1 , 0 0}$ & & $\mathbf{3 , 0 0}$ \\
\hline & Keterbatasan Fasilitas Agrowisata & &
\end{tabular}

Sumber : Data Primer diolah. 
(IFE) yang dilakukan yaitu terhadap faktorfaktor strategis internal yang terdiri dari kekuatan dan kelemahan dalam pengembangan Agrowisata Kebun Buah Cepoko.

Berdasarkan Tabel 4 menunjukkan bahwa skor total hasil analisis internal adalah 3,00 yang menandakan Agrowisata Kebun Buah Cepoko berada pada posisi sedang dalam memanfaatkan kekuatan untuk menghadapi kelemahan yang dihadapi dalam pengembangan Agrowisata Kebun Buah Cepoko. Adapun yang menjadi kekuatan utama yang ada pada Agrowisata Kebun Buah Cepoko yaitu lokasi yang strategis dengan skor internal 0,24, didukung dengan konsep Agrowisata yang berbasis konservasi, lingkungan hidup dan pendidikan dengan skor internal 0,21. Kemudian yang menjadi kelemahan utama pada kawasan agrowisata Kebun Buah Cepoko yaitu Keterbatasan anggaran dalam pengembangan Agrowisata dalam pengembangan Agrowisata dengan skor internal 0,21 dan Keterbatasan Fasilitas Agrowisata dengan skor internal 0,18 dan Variasi/ragam produk yang ditawarkan masih terbatas dengan skor internal 0,18.

Berdasarkan hasil penilaian IFAS, menunjukkan angka total skor pada kekuatan sebesar 1,76 dan angka total skor pada kelemahan sebesar 1,23. Hal ini menunjukkan bahwa Agrowisata Kebun Buah Cepoko memiliki kekuatan yang lebih besar dibandingkan kelemahannya dengan selisih sebesar 0,53 sehingga Agrowisata Kebun Buah Cepoko dapat memanfaatkan kekuatannya dalam mengembangkan Agrowisata.

Analisis kondisi eksternal dilakukan terhadap faktor-faktor strategis yang terdiri atas peluang dan ancaman dalam pengembangan Agrowisata Kebun Buah Cepoko. Ynag disajikan pada Tabel 5. Lingkungan Eksternal merupakan lingkungan yang ada diluar usaha yang menjadi peluang dan ancaman terhadap pengembangan Agrowisata Kebun Buah Cepoko. Hasil analisis faktor strategis eksternal peluang dan ancaman mendapat skor total analisis eksternalnya adalah 2,42 yang menandakan bahwa pengembangan Agrowisata Kebun Buah Cepoko berada pada posisi ekternal

Tabel 5. Matriks EFAS

\begin{tabular}{llccc}
\hline No & \multicolumn{1}{c}{ Faktor-Faktor Strategi Eksternal } & $\begin{array}{c}\text { Bobot } \\
(\mathbf{B})\end{array}$ & $\begin{array}{c}\text { Rating } \\
(\mathbf{R})\end{array}$ & B x R \\
\hline A & Peluang (Opportunities) & 0,10 & 3,26 & 0,33 \\
1 & Dukungan pemerintah terhadap Agrowisata & 0,10 & 3,02 & 0,29 \\
2 & Peningkatan jumlah pengunjung & 0,09 & 2,52 & 0,22 \\
3 & Kebutuhan berwisata masyarakat & 0,09 & 3,04 & 0,26 \\
4 & Dukungan masyarakat sekitar & 0,08 & 2,58 & 0,22 \\
& Gaya hidup masyarakat yang ingin kembali kealam (back to & & & $\mathbf{1 , 3 2}$ \\
\hline & nature) & & & \\
\hline & Total & 0,09 & 2,44 & 0,23 \\
\hline B & Ancaman (Threats) & 0,09 & 2,58 & 0,24 \\
1 & Adanya agrowisata sejenis di gunungpati & 0,08 & 2,10 & 0,17 \\
2 & Kondisi iklim yang tidak dapat diperediksi & 0,09 & 2,48 & 0,21 \\
3 & Perilaku konsumen & 0,09 & 2,84 & 0,26 \\
\hline 4 & Daya beli konsumen & & & $\mathbf{1 , 1 0}$ \\
\hline & Kekuatan yang dimiliki pesaing & $\mathbf{1 , 0 0}$ & & $\mathbf{2 , 4 2}$ \\
\hline & Total & &
\end{tabular}

Sumber : Data Primer diolah. 
yang sedang dalam memanfaatkan peluang untuk mengatasi ancaman yang dihadapi. Adapun peluang terbesar yang dimiliki dalam pengembangan Agrowisata Kebun Buah Cepoko adalah dukungan pemerintah terhadap Agrowisata dan Lokasi dapat diakses dengan mudah dengan sekor eksternal 0,32 hal ini sesuai dengan penelitian (Rinawati, 2014) tentang Strategi Pengembangan Agrowisata Perkebunan Gunung Mas PTPN VIII dimana lokasi yang dapat diakses dengan mudah merupakan peluang utama dalam pengembangan agrowisata. Kemudian yang menjadi ancaman utamanya adalahkekuatan yang dimiliki pesaing dengan skor eksternal 0,25 dan diikuti dengan kondisi iklim yang tidak dapat diprediksi dengan skor eksternal 0,23 .

Hasil penilaian terhadap EFAS menunjukkan angka total skor pada peluang sebesar 1,32 dan angka total skor pada tantangan/ancaman sebesar 1,10 sehingga menunjukkan bahwa peluang yang dimiliki Agrowisata Kebun Buah Cepoko lebih besar dari tantangan/ancaman ini menunjukkan peluang yang ada pada Agrowisata Kebun Buah Cepoko mampu mengatasi ancaman yang ada.

Berdasarkan hasil analisis SWOT dapat diketahui bahwa Agrowisata Kebun Buah Cepoko berada dalam kuadran I. Hal ini menunjukkan bahwa Agrowisata Kebun Buah
Cepoko berada pada situasi yang sangat menguntungkan karena memiliki kekuatan dan peluang yang dapat dimanfaatkan sebaikbaiknya. Dengan demikian, strategi yang sebaiknya digunakan adalah strategi yang mendukung pertumbuhan agresif dengan memanfaatkan kekuatan yang dimiliki untuk meraih dan memanfaatkan peluang yang ada (Rangkuti, 2006). Hal ini sesuai dengan penelitian Palit et al. (2017) yang meneliti tentang Strategi Pengembangan Kawasan Agrowisata Rurukan, kawasana agrowisata rurukan tersebut berada pada kuadran I dan Trimo (2018) meneliti tentang Kajian Strategi Pengembangan Agrowisata Kopi Luwak Manglayang, Kampung Pondok Buah - Batu Cikawari Desa Mekar Manik Kecamatan Cimeyan Kabupaten Bandung. Gambar posisi sel Agrowisata Kebun Buah Cepoko berdasarkan analisis SWOT dapat dilihat pada Ilustrasi 1.

\section{Strategi Pengembangan Agrowisata Kebun Buah Cepoko}

Beberapa alternatif strategi dalam pengembangan Agrowisata Kebun Buah Cepoko antara lain sebagai berikut:

1. Strategi SO

Strategi SO adalah strategi yang menggunakan kekuatan internal Kebun Buah Cepoko untuk memanfaatkan

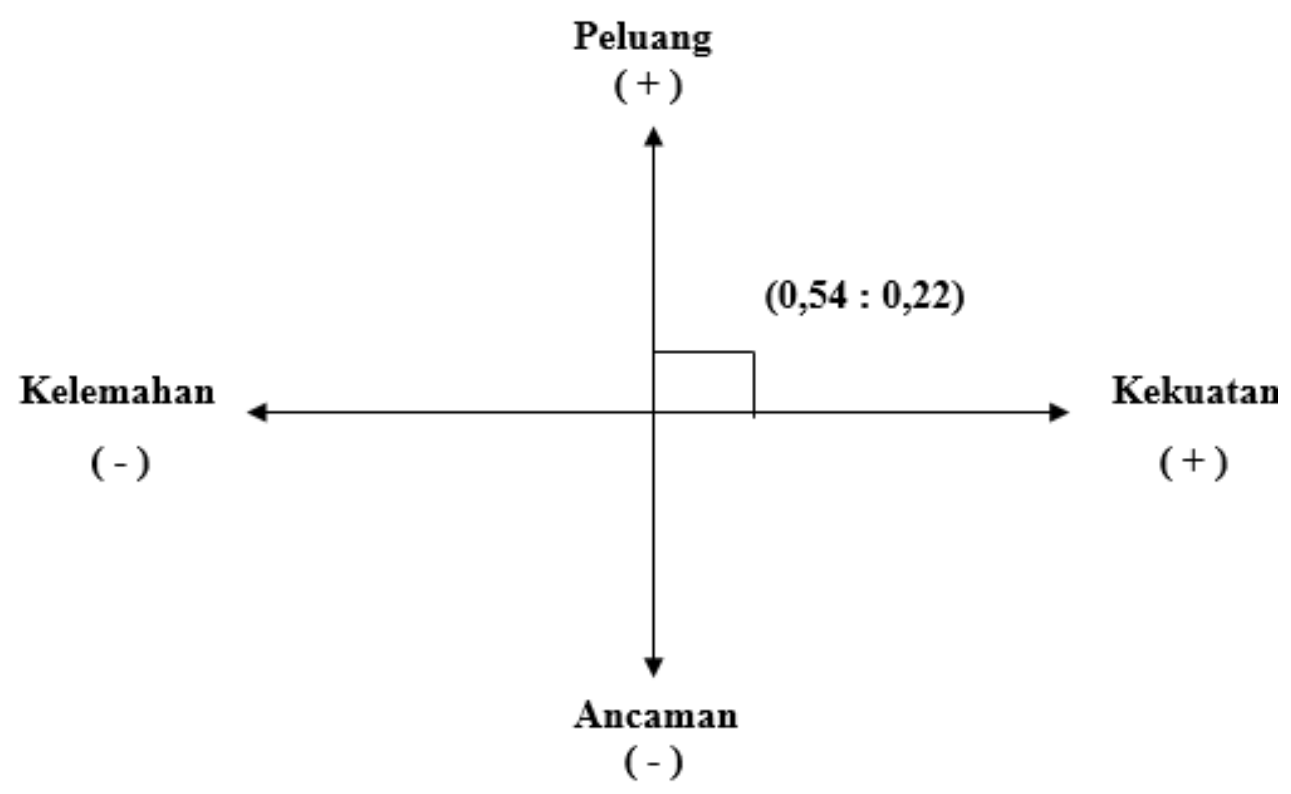

Ilustrasi 1. Posisi Agrowisata Kebun Buah Cepoko berdasarkan hasil analisis SWOT 
peluang eksternal yang ada agar memperoleh keuntungan bagi Kebun Buah Cepoko. Terdapat tiga alternatif strategi yang dapat dilakukan pada strategi SO yaitu:

a) Menggali potensi alam yang dimiliki dengan sumber daya alam yang ada, mengoptimalkan keunggulan pengelolaan agrowisata sehingga dapat meningkatkan jumlah pengunjung yang berkeinginan berwisata kealam.

b) Menambah fasilitas gazebo, parkir dan arena bermain anak agar pengunjung nyaman berwisata merupakan strategi yang dapat memanfaatkan peluang yang ada. Hal ini dikarenakan jumlah pengunjung yang terus bertambah serta tingginya keinginan konsumen untuk berwisata kealam (back to nature).

c) Melakukan kerjasama dengan warga setempat dan pemerintah disekitar lokasi usaha untuk menjaga dan memelihara infrastruktur jalan serta lalu lintasnya agar memudahkan konsumen yang akan berkunjung ke agrowisata. Lokasi Agrowisata Kebun Buah Cepoko yang strategis akan memberikan kemudahan bagi konsumen untuk berkunjung, karena didukung dengan infrastuktur dan akses jalan yang baik. Selain itu Agrowisata juga dapat memberikan kenyamanan kepada konsumen tidak hanya dalam kawasan wisata saja. Kenyamanan dapat dirasakan oleh konsumen mulai dari perjalanan menuju tempat wisata karena dilakukannya kerja sama dengan masyarakat setempat dan pemerintah.

2. Strategi WO

Strategi WO adalah strategi yang bertujuan untuk mengatasi kelemahan internal dengan memanfaatkan peluang eksternal yang dimiliki oleh Agrowisata Kebun Buah Cepoko. Strategi yang dapat digunakan oleh Agrowisata Kebun Buah Cepoko yaitu:

a) Melakukan promosi lebih aktif dan gencar melalui media elektonik. Strategi ini memanfaatkan peluang-peluang yang ada untuk mengatasi kelemahan yang dimiliki. Peluang tersebut seperti faktor minat konsumen yang mulai beralih ke wisata back to nature, jumlah wisatawan yang meningkat terutama pada saat long weekend. Dengan demikian, kelemahan yang ada dapat dikurangi dengan melakukan promosi usaha, karena banyaknya konsumen yang ingin berwisata dengan suasana alamiah. Penyebaran brosur dan leaflet juga harus dilakukan tidak hanya di kawasan wisata saja tetapi juga menyebarkan sampai ke daerah-daerah lainnya. Salah satu cara pomosi yang juga efektif adalah dengan mengadakan acara televisi yang sedang banyak digemari masyarakat dengan lokasi di Agrowisata Kebun Buah Cepoko, dikarenakan dalam acara tersebut dapat dipromosikan lokasi Agrowisata Kebun Buah Cepoko, produk-produk yang ada di Kebun Buah Cepoko Promosi usaha yang dilakukan juga harus memperhatikan fasilitas yang ditawarkan, dikarenakan promosi yang baik juga harus diiringi dengan pengembangan produk yang kontinyu. Dengan demikian, fasilitas wisata harus memiliki kualitas yang baik dan sesuai dengan yang dipromosikan sehingga konsumen merasa puas dengan fasilitas yang ditawarkan seperti pada promosi yang diiklankan.

b) Menambah personil keamanan dan parkir dengan melibatkan masyarakat setempat pada saat kondisi ramai untuk menjamin keamanan berwisata.

c) Meningkatkan kualitas sumber daya manusia.

3. Strategi ST

Strategi ST adalah strategi yang menggunakan kekuatan perusahaan untuk menghindari berbagai ancaman yang ada. Strategi yang dapat digunakan oleh perusahaan, yaitu:

a) Menambah daya tarik wisata seperti wisata petik buah, taman bunga dan pembuatan area outbond untuk anak- 
anak agar mampu bersaing dengan wisata sejenis.

b) Meningkatkan mutu pelayanan jasa dan kualitas dari fasilitas wisata yang ada dengan ciri khas tersendiri sehingga konsumen merasa puas dengan pelayanan dan fasilitas yang ada. Tingginya tingkat persaingan bisnis dan banyaknya tempat wisata yang menawarkan wisata alam, menyebabkan konsumen memiliki banyak pilihan untuk berwisata ke tempat mana saja yang diinginkannya. Hal ini menyebabkan setiap usaha yang menawarkan produk jasa yang hampir serupa harus melakukan suatu strategi dengan memanfaatkan kekuatan mereka masingmasing untuk menghadapi persaingan bisnis. Kekuatan yang dimiliki oleh Agrowisata Kebun Buah Cepoko yaitu lokasi yang strategis dan Peningkatan mutu pelayanan jasa dan kualitas dari fasilitas wisata adalah sesuatu yang dapat dilakukan agar tidak mengalami penurunan tingkat konsumen dalam persaingan bisnis tersebut.

\section{Strategi WT}

Strategi WT menunjukkan strategi yang meminimalkan kelemahan perusahaan untuk menghindari berbagai ancaman yang ada. Strategi yang dapat digunakan, yaitu: Meningkatkan sumber daya manusia dan manejemennya dengan pelatihan khusus untuk meningkatkan produktivitas karyawan dan memiliki keterampilan dan pengetahuan mengenai pariwisata untuk meningkatkan mutu pelayanan.

\section{SIMPULAN DAN SARAN}

\section{Simpulan}

1. Indeks kepuasan pengunjung Agrowisata Kebun Buah Cepoko, diketahui nilai CSI adalah 77,81 \%. Nilai indeks kepuasan $77,81 \%$ mempunyai arti bahwa secara keseluruhan pengunjung Agrowisata Kebun Buah Cepoko puas terhadap atribut Agrowisata Kebun Buah Cepoko.
2. Posisi Agrowisata Kebun Buah Cepoko berdasarkan kondisi internal dan eksternal berada pada kuadran I yang menunjukkan bahwa Agrowisata Kebun Buah Cepoko berada pada situasi yang sangat menguntungkan karena memiliki kekuatan dan peluang yang dapat dimanfaatkan sebaik-baiknya dengan melakukan strategi yang mendukung pertumbuhan agresif.

3. Strategi pengembangan Agrowisata Kebun Buah Cepoko yang dapat dilakukan yaitu:

a) Meningkatkan mutu pelayanan jasa dan kualitas dari fasilitas wisata yang ada dengan ciri khas tersendiri sehingga konsumen merasa puas dengan pelayanan dan fasilitas yang ada.

b) Menggali potensi alam yang dimiliki dengan sumber daya alam yang ada, mengoptimalkan keunggulan dan pengelolaan agrowisata.

c) Menambah daya tarik wisata seperti wisata petik buah, taman bunga dan pembuatan area outbond untuk anakanak.

d) Melakukan kerjasama dengan warga setempat disekitar lokasi usaha untuk menjaga dan memelihara infrastruktur jalan serta lalu lintasnya agar memudahkan konsumen yang akan berkunjung ke agrowisata.

e) Meningkatkan sumber daya manusia dan manejemennya dengan pelatihan khusus untuk meningkatkan produktivitas karyawan dan memiliki keterampilan dan pengetahuan mengenai pariwisata.

f) Melakukan promosi lebih aktif dan gencar melalui media elektonik.

g) Menambah personil keamanan dan parkir dengan melibatkan masyarakat setempat pada saat kondisi ramai untuk menjamin keamanan berwisata.

\section{Saran}

1. Menerapkan strategi yang telah diperoleh dan melakukan evaluasi secara berkala 
untuk merinci secara tepat dan jelas, bagaimana realisasi sesungguhnya dari strategi pengembangan usaha yangtelah dipilih.

2. Agrowisata Kebun Buah Cepoko hendaknya melakukan kerjasama dengan objek wisata lain yang ada disekitar Kebun Buah Cepoko agar Agrowisata Kebun Buah Cepoko semakin dikenal.

3. Agrowisata Kebun Buah Cepoko hendaknya melakukan kegiatan pengembangan produk dengan melakukan pengolahan hasil pertanian (membuat jus buah, selai, dodol, manisan dan lain-lain).

4. Agrowisata Kebun Buah Cepoko hendaknya memperbaiki tempat parkir untuk kenyamanan pengunjung.

\section{DAFTAR PUSTAKA}

Anggraini, D. L., P. Doeranto, dan D. M. Ikasari. 2015. Analisis persepsi konsumen menggunakan metode Importance Performance Analysis (IPA) dan Customer Satisfication Index (CSI). J. Industri. 4(2): 74-81.

Aritonang, R. L. 2005. Kepuasan Pelanggan. PT Gramedia Pustaka Utama, Jakarta.

Budiarti, T. Suwarto, dan I. Muflikhati. 2013. Pengembangan agrowisata berbasis masyarakat pada usahatani terpadu guna meningkatkan kesejahteraan petani dan keberlanjutan sistem pertanian. JIPI. 18(3): 200-217.

David, F. R. 2002. Manajemen Strategis. Prenhallindo, Jakarta.

Departemen Pertanian. 2004. Strategi Pengembangan Wisata Agro di Indonesia.

Durbarry, R. 2016. Research Methods for Tourism Students. Taylor \& Francis Ltd, London.

Habiby, W. N. 2017. Statistika Pendidikan. Muhammadiyah University Press: Surakarta,
Juanda, B. 2009. Metode Penelitian Ekonomi dan Bisnis. IPB Press, Bogor.

Jolly, A. D. and A. K. Reynolds. 2005. Consumer Demand For Agricultural And On-Farm Nature Tourism. Uc Small Farm Center Research Brief. Retrieved from http://sfp.ucdavis.edu/ files/143466.pdf

Palit, I. G., C. Talumingan, dan G.A.J. Rumagit. 2017. Strategi pengembangan kawasan Agrowisata Rurukan. Agri-Sosio Ekonomi Unsrat. 13 (2): 21-34.

Puspitasari, L. dan R. Dwiastuti. 2018. Analisis Kelayakan Finansial Kebun Wisata Strawberry (Kasus di Kebun Wisata Strawberry Highland). JEPA, 2(3): 187-193.

Putra, S. A. A. A. P., I. G. N. A. Aviantara, dan I. W. Widia. 2015. Strategi pengembangan agrowisata berbasis analisis SWOT di Unit Wisata Agro Mandiri. J. BETA. 3(2): 1-9.

Rangkuti, F. 2006. Analisis SWOT: Tehnik Membedah Kasus Bisnis - Reorientasi Konsep Perencanaan Strategis untuk menghadapi Abad 21. PT. Gramedia Pustaka Utama, Jakarta.

Rinawati, R. 2014. Strategi pengembangan Agrowisata Perkebunan Gunung Mas PTPN VIII (Studi Kasus di Unit Usaha Perkebunan Gunung Mas PTPN VIII, Kecamatan Cisarua, Kabupaten Bogor, Provinsi Jawa Barat). Agric.Sci.J. 1(4): 18-27.

Saraswati, I. A. S., U. N. Vipriyanti, dan C. Kardi. 2017. Strategi pengembangan Agrowisata Strawberry Stop berbasis kepuasan pengunjung. J. Agrimeta. $7(13): 20-29$.

Sunanto dan H. Juddawi. 2011. Analisis kelayakan usaha dan pemasaran hasil durian (Durio zibethinus murray) di Kabupaten Palopo Sulawesi Selatan. J. SEPA. 8(1): 1-8. 
Syukri, S. H. A. 2014. Penerapan Customer Satisfication Index (CSI) dan analisis GAP pada kualitas pelayanan Trans Jogja. J. Ilmiah Teknik Industri, 13(2): 103-111.

Tangkere, E. G. dan L. W. Sondak. 2017. Tingkat kepuasan pengunjung terhadap kualitas pelayanan daerah Wisata Puncak Temboan Tomohon. J. AgriSosioEkonomi Unsrat. 13(1): 35-46.

Trimo, L., G. W. Mukti, dan H. Fauziana. 2018. Kajian strategi pengembangan Agrowisata Kopi Luwak (Studi kasus Kopi Luwak Manglayang Kampung Pondok Buahbatu Cikawari Desa Mekarmanik Kecamatan Cimenyan Kabupaten Bandung. J. Agricore. 3(2): 525-536.
Wicaksana, B. E., A. W. Muhaimin, dan D. Koestiono. 2013. Analisis sikap dan kepuasan petani dalam menggunakan benih kentang bersertifikat (Solanum tuberosum L.) (kasus di Kecamatan Bumiaji, Kota Batu). J. HABITAT. 24(3): $184-193$. 